\title{
Seborrheic dermatitis: is there room for systemic corticosteroids?
}

\section{Dermatite seborréica: ainda há espaço para corticoesteróides sistêmicos?}

\author{
Kleyton de Carvalho Mesquita ${ }^{1}$ \\ Izelda Maria Carvalho Costa ${ }^{3}$
}

We have read the Continuing Medical Education article about seborrheic dermatitis (SD) with great interest. This is a common dermatosis in dermatologic practice. Mild cases may be easily managed with topical medication, as detailed by Sampaio et al. ${ }^{1}$ Nevertheless, recalcitrant moderate to severe patients may require systemic therapy. Itraconazole has been considered the treatment of choice due to its anti-inflammatory, lipophilic and keratinophilic properties, as well as reduced hepatotoxicity. $^{2-4}$ Systemic corticosteroids (CS) have been less frequently cited in current national and international literature. However, they must be considered among the systemic options for SD treatment, usually in recalcitrant moderate to severe cases. ${ }^{5}$ Prolonged and/or frequent use should be avoided due to their well-known associated risks. Prednisone $0.5-1 \mathrm{mg} / \mathrm{kg} / \mathrm{day}$ (or equivalent) for a limited period and with gradual tapering is habitually the first option. We illustrate this with an immunocompetent male patient with severe SD (Figure 1) who did not show a satisfactory clinical response to topical therapy and was financially impaired to undergo treatment with oral azoles. After 15 days of prednisone $0.5 \mathrm{mg} / \mathrm{kg} / \mathrm{day}$, he showed noticeable clinical improvement (Figure 2). Systemic CS was gradually tapered and maintenance treatment

\section{REFERENCES}

1. Sampaio AL, Mameri AC, Vargas TJ, Ramos-E-Silva M, Nunes AP, Carneiro SC. Seborrheic dermatitis. An Bras Dermatol. 2011;86:1061-1074.

2. Gupta AK, Bluhm R. Seborrheic dermatitis. J Eur Acad Dermatol Venereol. 2004;18:13-26.

3. Gupta AK, Bluhm R, Cooper EA, Summerbell RC, Batra R. Seborrheic dermatitis. Dermatol Clin. 2003;21:401-12.

4. Das J, Majumdar M, Chakraborty U, Majumdar V, Mazumdar G, Nath J. Oral itraconazole for the treatment of severe seborrhoeic dermatitis. Indian J Dermatol. 2011;56:515-6

5. Berth-Jones J. Eczema, Lichenification, Prurigo and Erythroderma. In: Burns T, Breathnach S, Cox N, Griffiths C, eds. Rook's Textbook of Dermatology. Oxford: Wiley-Blackwell; 2010. p 23.29-23.34.

\author{
Ana Carolina de Souza Machado Igreja ${ }^{2}$
}

with topical CS and antifungals prevented relapses. Therefore, we consider oral CS for the initial treatment of patients with exuberant and refractory SD and those for whom oral antifungals are contraindicated or do not reach satisfactory control of the dermatosis. We additionally highlight that phototherapy (Narrow Band UVB or oral psoralen plus UVA) must also be considered among the therapeutic options of $\mathrm{SD} .^{2}$

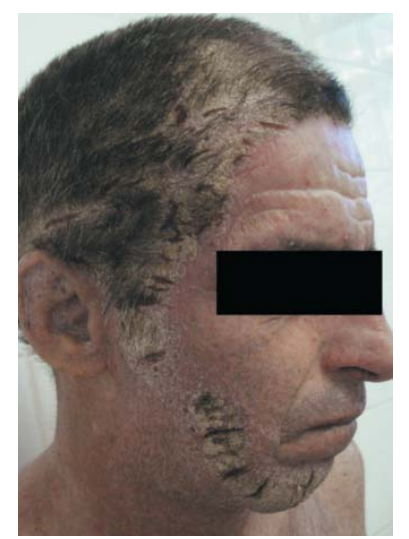

FiguRE 1: Forty-three year old male patient presenting exuberant SD lesions: erythematous plaques, thick greasy scales and fissures on the face and scalp

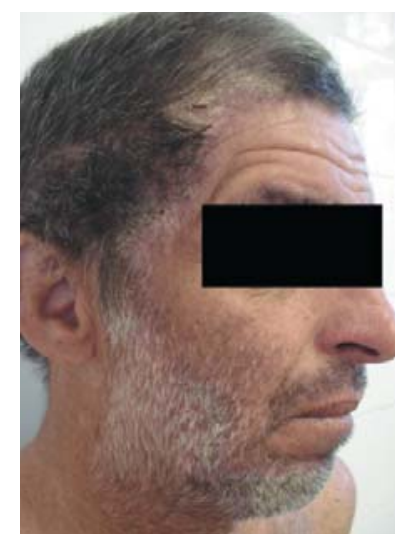

Figure 2: Significant clinical improvement after 15 days of oral prednisone $(0.5 \mathrm{mg} / \mathrm{kg} / \mathrm{day})$
MAILING ADDRESS:

Kleyton de Carvalbo Mesquita

QE 34, conjunto P, casa 25. Guará II.

71.065-162 Brasília-DF - Brasil.

E-mail:kleyton.mesquita@gmail.com

Received on 24.02.2012

Approved by the Advisory Board and accepted for publication on 04.03.2012.

* Work conducted at Ceilandia Regional Hospital (HRC) and University Hospital of Brasília (HUB/UnB) - Brasília (DF), Brazil.

Financial Support: None.

Conflict of Interest: None.

M.Sc. Student in Health Sciences - University of Brasília (UnB) - Dermatologist, Health State Secretariat of the Federal District (SES-DF) - Brasília (DF), Brazil. Physician, Dermatology Residency Program, University Hospital of Brasília/University of Brasília (UnB) - Brasília (DF), Brazil.

PhD in Dermatology, Federal University of Sao Paulo (Unifesp). Professor of Dermatology, University of Brasília (UnB) - Brasília (DF), Brazil. 